(1)

\title{
Prostate cancer genomics by high-throughput technologies: genome-wide association study and sequencing analysis
}

\section{Hidewaki Nakagawa}

Laboratory for Genome Sequencing Analysis, RIKEN Center for Integrative Medical Sciences, Yokohama, Japan
Correspondence should be addressed to H Nakagawa

Email

hidewaki@ims.u-tokyo.ac.jp

\begin{abstract}
Prostate cancer (PC) is the most common malignancy in males. It is evident that genetic factors at both germline and somatic levels play critical roles in prostate carcinogenesis. Recently, genome-wide association studies (GWAS) by high-throughput genotyping technology have identified more than 70 germline variants of various genes or chromosome loci that are significantly associated with PC susceptibility. They include multiple $8 q 24$ loci, prostate-specific genes, and metabolism-related genes. Somatic alterations in PC genomes have been explored by high-throughput sequencing technologies such as whole-genome sequencing and RNA sequencing, which have identified a variety of androgen-responsive events and fusion transcripts represented by E26 transformation-specific (ETS) gene fusions. Recent innovations in high-throughput genomic technologies have enabled us to analyze PC genomics more comprehensively, more precisely, and on a larger scale in multiple ethnic groups to increase our understanding of PC genomics and biology in germline and somatic studies, which can ultimately lead to personalized medicine for PC diagnosis, prevention, and therapy. However, these data indicate that the PC genome is more complex and heterogeneous than we expected from GWAS and sequencing analyses.
\end{abstract}

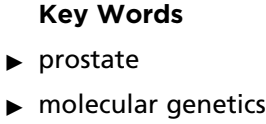

Endocrine-Related Cancer (2013) 20, R171-R181

\section{Introduction}

Prostate cancer (PC) is the most common malignancy in men and the second leading cause of cancer-related deaths in Western countries. Incidence and mortality rates vary widely across geographic regions and ethnic groups (Gronberg 2003). In particular, Asian populations have a substantially lower incidence rate than Caucasians or African Americans, indicating the contribution of different genetic backgrounds to PC susceptibility (Gronberg 2003, Schaid 2004, Nakagawa et al. 2012). Although the precise mechanisms of prostate carcinogenesis have not been fully elucidated, it is evident that genetic factors play important roles in PC etiology. A positive family history of $\mathrm{PC}$ has been recognized as one of the most important risk factors for PC, as well as African ethnicity and older age (Schaid 2004); twin studies have suggested that the contribution of genetic factors to the development of PC is larger than in other types of common human tumors (Lichtenstein et al. 2001). Over the past 20 years, genetic research by linkage analysis on several hereditary PC families had been conducted to clarify PC genomics and to identify genes responsible for PC susceptibility (Schaid 2004). This strategy identified

Published by Bioscientifica Lto. 
some candidate genes predisposing to hereditary PC, but they were not replicated in other studies, and this approach was not successful for understanding PC genomics. However, recent genome-wide association studies (GWAS) using high-throughput genotyping technologies on several thousand samples of several ethnic groups have successfully identified more than 70 singlenucleotide polymorphisms (SNPs) of various genes or chromosome loci that are known to be significantly associated with PC susceptibility (Amundadottir et al. 2006, Gudmundsson et al. 2007, Haiman et al. 2007, Eeles et al. 2008, 2013, Nakagawa et al. 2012).

On the other hand, somatic events in the development and progression of PC have been recently explored more comprehensively through genomic technologies. NKX3.1 (NKX3-1) loss and PTEN loss or point mutations were frequently observed in advanced PCs. The androgen/androgen receptor (AR) signaling pathway plays a central role in PC development and progression, and PC growth is usually androgen-dependent. Hence, most of the patients with relapsed or advanced disease respond well to androgen-ablation therapy (castration). Nonetheless, they eventually acquire castration resistance (CR) and progress to a more aggressive phenotype (Scher \& Sawyers 2005). In this phase, AR amplification (10-20\%) or AR point mutations $(<10 \%)$ are frequently observed (Taplin et al. 1995, Bubendorf et al. 1999), indicating that somatic AR alterations play a critical role in CRPC progression (Scher \& Sawyers 2005). Furthermore, a new link was established in 2005 between the androgen signaling pathway and PC through the discovery of a genetic rearrangement that drives the fusion of two genes: the androgen-regulated gene TMPRSS2 and the E26 transformation-specific (ETS) transcription factor $E R G$ (Tomlins et al. 2005).

Cancer is essentially a disease of the genome that develops and evolves with the accumulation of a variety of somatic mutations with the background of germline variants, and these genomic alterations have now been targeted for cancer treatment and diagnosis. Recent explosive advances of high-throughput genotyping and high-throughput sequencing technologies (next-generation sequencing (NGS)) with bioinformatics approaches enable us to comprehensively analyze a number of cancer genomes. GWAS, whole-genome sequencing (WGS), whole exome sequencing (WES), and RNA sequencing (RNA-Seq) have now been conducted for many types of cancer genomes worldwide, including the International Cancer Genome Consortium (ICGC; Hudson et al. 2010) and the Prostate Cancer Association Group to
Investigate Cancer Associated Alterations in the Genome (PRACTICAL Consortium; Kote-Jarai et al. 2008, Eeles et al. 2013), to explore cancer genomic alterations and diversity. The findings from GWAS using high-throughput genotyping contribute to a better understanding of prostate carcinogenesis and potential application for PC risk prediction and prevention, whereas the findings from somatic mutation analysis, such as WGS and RNA-Seq, may contribute to the discovery of novel therapeutic targets and biomarkers for PC and molecular subclassifications of PC (Fig. 1). This genomic research could ultimately lead to personalized medicine for PC diagnosis, treatment, and prevention. This review describes how recent high-throughput technologies have been applied to PC genomics research, in germline and somatic studies, and what has been achieved to date.

\section{GWAS by high-throughput genotyping to identify germline PC susceptibility loci}

GWAS is typically based on a case-control design in which around a hundred thousand SNPs across the human genome are genotyped, and it can scan for germline variants that are associated with disease risk. Such associations are consistent with the 'common diseasecommon variant' hypothesis that assumes that genetic influences on susceptibility to common diseases such as PC are attributable to some number of common variants present in more than $5 \%$ of the population (Manolio 2010). GWAS for PC have been remarkably successful in identifying more than 70 common genetic variants or loci, which is quite high compared with the corresponding numbers for other types of cancers and other common diseases. A Manhattan plot of a PC GWAS (Fig. 1) typically indicates many peaks of $-\log (P$ value $)$ across the genome, including an extremely high peak (low $P$ value for the association) in chromosome $8 q 24$. Subsequent replication and follow-up studies have identified additional associated variants that show genome-wide significance with $P$ values $<5 \times 10^{-8}$ after adjustment for multiple testing. Recent meta-analyses combining several GWAS cohorts in several ethnic groups (more than 50000 samples) identified additional PC-susceptibility genes or variants (Eeles et al. 2009, 2013, Kote-Jarai et al. 2011); larger meta-analysis are now being conducted worldwide and are expected to identify additional PC-susceptibility loci and reach more than 100 PC-susceptibility loci in the near future. As PC incidence and heritability remarkably differ for each race, it is important to perform meta-GWAS on several ethnic

Published by Bioscientifica Ltd. 


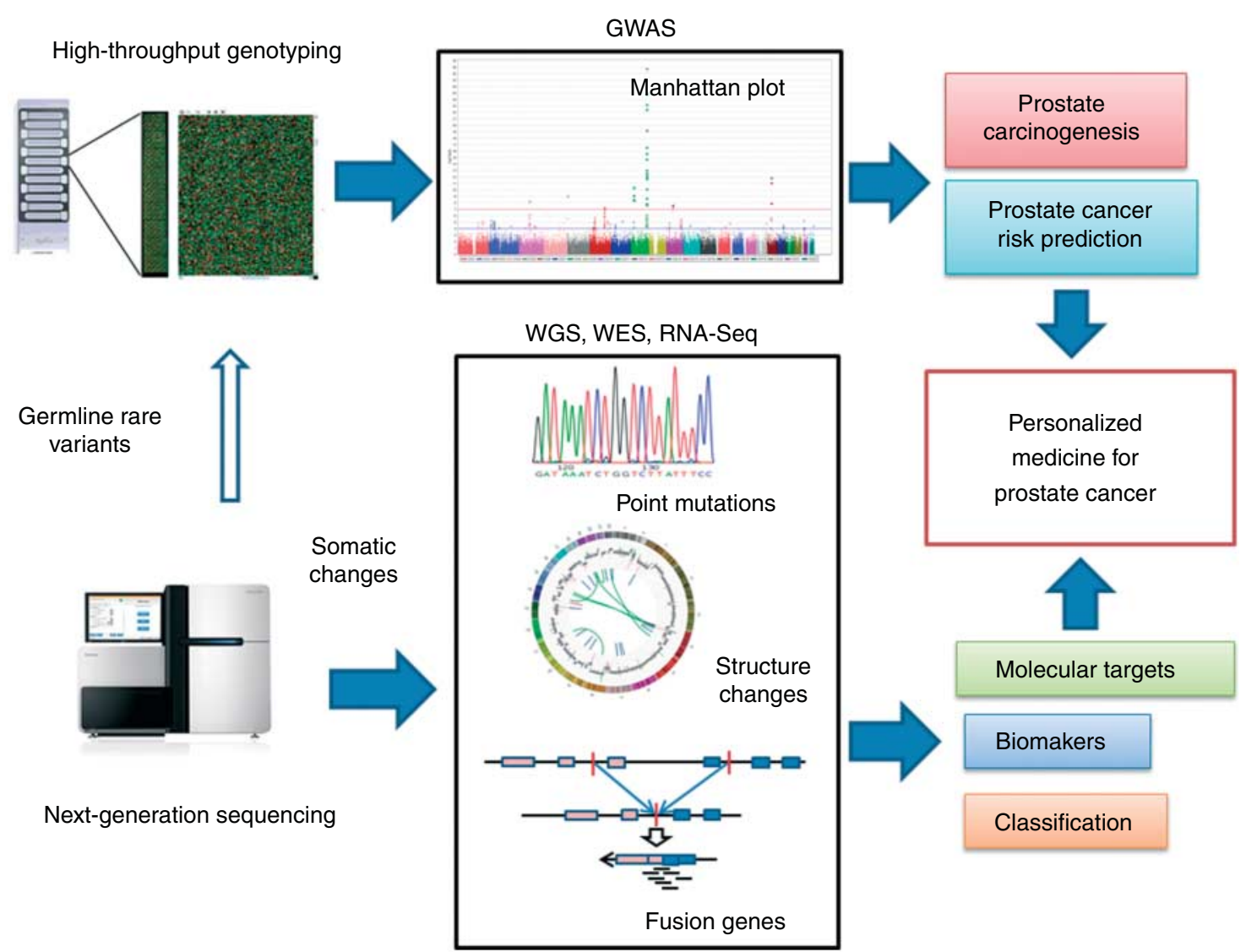

\section{Figure 1}

Recent innovations in high-throughput genomic technologies enable us to analyze prostate cancer genomics more comprehensively, more precisely, and on a larger scale. High-throughput genotyping technologies can genotype 60-100 K SNPs and are applicable for GWAS on 10000 samples. Next-generation sequencing (NGS) can analyze whole genomes ( $3 \mathrm{~Gb}$ ) and

or racial groups such as Asian and African populations (Takata et al. 2010, Haiman et al. 2011). However, many of the identified PC-susceptibility variants are located in the intergenic regions, as observed for other disease GWAS, and there are variants for which the biological significance has been proved to be associated with PC. The function or biological significance of only a few variants or genes has been elucidated so far. The greatest challenge of the GWAS loci for prostate genomics is to understand the functional consequences of these many PC-associated loci and to attempt to further understand PC biology and prostate carcinogenesis (Freedman et al. 2011). Identification of additional PC-susceptibility loci in larger multi-ethnic GWAS cohorts and biological insights from such functional analysis on GWAS loci can be translated into clinical benefits, including reliable risk-prediction biomarkers and effective strategies for screening and prevention of PC. the whole transcriptome on dozens of samples to identify point mutations, structural changes, and fusion genes comprehensively. Rare germline variants discovered by NGS have also been analyzed by high-throughput genotyping technologies for GWAS targeting of rare variants.

\section{Chromosome $8 q 24$ region}

Many GWAS in multiple ethic groups reported strong and consistent association of multiple variants at chromosome 8q24 with PC susceptibility (Gudmundsson et al. 2007, Haiman et al. 2007, Yeager et al. 2007, Al Olama et al. 2009). This region contains various independent PC-susceptibility loci within an $\sim 1 \mathrm{Mb}$ segment, and some of them were found to be significantly associated with other types of cancers such as colon cancer and breast cancer (Easton et al. 2007, Tomlinson et al. 2007). However, no gene has been annotated in this $\sim 1 \mathrm{Mb}$ region, and its biological significance in cancer remains unclear. There are at least five separate loci (Region1-3 or Block1-5) associated with PC susceptibility in this region (Ghoussaini et al. 2008). The MYC proto-oncogene is located at $\sim 200 \mathrm{~kb}$ downstream, and recent studies have indicated that one of the loci at $8 q 24$ (rs6983267

Published by Bioscientifica Ltd 
represents Region1/Block5) could be associated with the WNT signaling pathway (Tuupanen et al. 2009) in colorectal cancer and with MYC expression in several cancers (Pomerantz et al. 2009). The association of its most centromeric region (Region2: Chr8: 128.14-128.28 Mb) with PC is stronger in Japanese and African populations, and this region was transcribed as an $\sim 10 \mathrm{~kb}$ intron-less long non-coding RNA (ncRNA). The expression of this ncRNA was upregulated in PC cells and its precursor lesions, and it is likely to be involved with transcriptional AR activity (Chung et al. 2011). Another study reported that a variant on Region2 was correlated with serum testosterone levels (Chu et al. 2010), and because Region2 is associated only with PC, not with breast cancer and others, it is likely to be specifically involved with PC through the androgen/AR signaling pathway.

\section{Prostate-specific genes}

Several GWAS of PC identified a variant (rs2735839) of KLK3 at chromosome 19q13, encoding prostate-specific antigen (PSA) as an indicator of PC susceptibility (Eeles et al. 2008). However, several groups observed an association between rs2735839 and serum PSA levels (Gudmundsson et al. 2010), and this genetic variant may be merely associated with the likelihood of diagnosis by virtue of its link with serum PSA levels. A SNP at chromosome 10q11 (rs10993994) was validated to be associated with several GWAS in some populations (Eeles et al. 2008, Thomas et al. 2008). It is located at the $5^{\prime}$ region of the MSMB gene, encoding $\beta$-microseminoprotein. Fine mapping and functional analysis demonstrated that this SNP could influence the transcriptional activity of the promoter of MSMB (Chang et al. 2009). MSMB is synthesized by epithelial cells in the prostate gland and secreted into the seminal plasma, and its expression progressively decreased during development of PC from early to late stages, suggesting its potential effect as a tumor suppressor (Beke et al. 2007). Some GWAS showed the consistent association of rs1512268 at chromosome $8 p 21$ with PC susceptibility, which represents a $57 \mathrm{~kb}$ genetic region in which the NKX3.1 gene is solely annotated (Eeles et al. 2009, Takata et al. 2010). NKX3.1 is exclusively expressed in the prostate tissue, and variants in the $5^{\prime}$-UTR of NKX3.1 regulate the proximal promoter activity of the NKX3.1 gene (Akamatsu et al. 2010). NKX3.1 is an androgen-regulated homeobox gene, which plays a key role in the regulation of growth and differentiation of prostate epithelium in a normal prostate and marks a stem cell population that functions during prostate regeneration (Wang et al. 2009). Iroquois homeobox 4 (IRX4) at chromosome 5p15 was also identified as a PC-susceptibility gene by GWAS (Nguyen et al. 2012), and it is specifically expressed in the adult prostate and heart, suggesting its involvement with the development of the prostate and heart. The associated variants are located at the $5^{\prime}$ region of the IRX4 gene, and regulate the transcriptional activity of IRX4 through direct interaction with the vitamin D pathway (Nguyen et al. 2012). GWAS have demonstrated that these prostatespecific genes are strongly associated with prostate carcinogenesis as well as prostate development.

\section{Metabolism-related genes}

It is interesting that GWAS for PC identified several loci or SNPs that were validated to be inversely associated with type 2 diabetes (T2D). Epidemiological studies suggest that men with T2D are less likely to develop PC than nondiabetic men (Bonovas et al. 2004). GWAS identified variants of the hepatocyte nuclear factor 1 homeobox B gene $(H N F 1 B)$, which were also related to T2D predisposition (Sun et al. 2008). These variants were shown to be associated with decreased risk of PC. HNF1B encodes a transcription factor, which plays a key role in the development and function of the pancreas and kidney by regulating the expression of numerous genes in these tissues (Pontoglio 2000). HNF1B was previously shown to be mutated in individuals with maturity-onset diabetes of the young type 5 (MODY5; Lindner et al. 1999). Interestingly, this variant at $H N F 1 B$ was also found to be associated with the risk of endometrial cancer in women, which is also thought to be dependent on some metabolic and hormone factors, as well as PC in men (Spurdle et al. 2011). GWAS showed that variants of juxtaposed with another zinc finger 1 (JAZF1) were also significantly associated with $\mathrm{T} 2 \mathrm{D}$ and associated with decreased risk of PC (Thomas et al. 2008). JAZF1 encodes a nuclear protein with three zinc fingers and functions as a transcriptional repressor and it may be involved in lipid metabolism in the liver and adipocytes (Li et al. 2011). JAZF1 variants were also shown to be associated with human height, supporting a role for this gene in the regulation of growth and metabolism (Soranzo et al. 2009). Thus, it appears possible that genetic variations in JAZF1 and $H N F 1 B$ may influence PC risk by changing the levels of hormones or growth-related factors previously suggested to be related to T2D. A GWAS identified that rs339331 at $6 q 22$ was significantly associated with PC susceptibility (Takata et al. 2010), and this locus includes

Published by Bioscientifica Ltd 
the $G$ protein-coupled receptor, family C, group 6, member A gene (GPRC6A). Gprc6a-null mice exhibited a metabolic syndrome characterized by impaired bone mineralization, increased fat mass, fatty liver, glucose intolerance, testicular feminization, and abnormal steroidogenesis (Pi et al. 2008), indicating that it can affect PC susceptibility by altering GPRC6A-mediated sex hormone production and metabolic pathways. Diet and lifestyle are now proposed to be critical risk factors for PC development, and indeed, in Asia, there is rapidly increasing incidence of PC partially due to the prevalence of a Western lifestyle, which includes high consumption of a high-fat diet. These interesting observations illustrate a biological phenomenon connecting metabolism and prostate carcinogenesis.

\section{Inflammation-related gene}

Japanese GWAS on PC identified a PC-susceptibility locus at 19q13.4 (rs103294), and this SNP is located in the FOXP4 gene (Takata et al. 2010). The FOXP family of forkhead transcription factors are essential for normal T-cell lineage development. A new member of the FOXP family, FOXP4, has also been reported to be dispensable for T-cell development, and it may be involved in the immune response to pathogen infection (Wiehagen et al. 2012). GWAS on Chinese PCs identified a PC-susceptibility locus at 19q13.4 (rs103294), and this SNP was tightly linked with a $6.7 \mathrm{~kb}$ deletion that removed the first six exons of leukocyte immunoglobulin-like receptor, subfamily A, member 3 (LILRA3) and induced the loss of its expression in $\mathrm{T}$ cells (Xu et al. 2012). The LIR family members, including LILRA3, bind to major histocompatibility complex antigens and regulate the immune and inflammatory response. Although the role of LILRA3 in prostate carcinogenesis is largely unknown, these findings suggest a potential role in chronic inflammation or the immune response in prostate carcinogenesis.

\section{Variants associated with aggressive PCs}

It remains unclear whether these genetic variants are associated with PC aggressiveness. PC is primarily a disease associated with old age, and many indolent PC cases in elderly people are subject to a watch-and-wait strategy without any PC treatment (Albertsen 2010). The rate of latent PC in autopsies may be as high as $80 \%$ by the age of 80 years (Konety et al. 2005), and PC is a very 'common' disease in older men. Hence, distinguishing between indolent PC and aggressive PC, which requires treatment, including medical castration, surgery, and radiation therapy, and predicting the risk of aggressive PC are very important current goals in PC research and clinics. Recent meta-analysis of GWAS showed that rs 4054823 at $17 p 12$ is associated with aggressive disease of PC, but there is no annotated gene around this SNP and no explanation for its biological association with PC aggressiveness (Xu et al. 2010). Another meta-analysis identified rs11672691 at $19 q 13$ as being significantly associated with aggressive PCs, but this association was also observed in indolent PCs, and the responsible genes and biological significance of this locus was not clear (Al Olama et al. 2013). To date, most of the PC-susceptibility loci or SNPs have not been significantly associated with aggressive PC disease specifically.

\section{PC risk estimation by multiple SNPs}

GWAS have identified more than 50 variants or loci significantly associated with PC risk, but each of them has limited use in the assessment of PC risk in an individual because each of these genetic markers confers a modest effect (OR: 1.1-2.0). It is required for clinical use of these risk variants to combine individual variants for PC risk assessment (Manolio 2010). Zheng et al. (2008) combined five variants for PC risk assessment plus a family history of $\mathrm{PC}$ and confirmed a cumulative and significant association with PC. However, several studies using five or more SNPs have since indicated that the area under the curve (AUC) in the ROC curve was around 0.6, and this SNP panel may have limited clinical utility (Nam et al. 2009, Zheng et al. 2009). Even when the sample number was increased, the AUC was predicted to be $<0.7$ (Chatterjee et al. 2013). The AUC of the PSA test was found to be 0.65-0.7; to apply the risk estimation model for PC screening, the AUC should be larger than that of PSA. Otherwise, the risk estimation model should focus on individuals with gray-zone or normal-range PSA levels, in which the efficiency of PSA testing to detect PC is questionable (Akamatsu et al. 2012). And also it is important to construct a SNP prediction model for each ethnic group because the frequency and OR of each SNP is different in each ethnic group.

\section{Rare variants associated with PC susceptibility}

GWAS have thus far focused on common SNPs, but most of these disease-associated SNPs have a very small effect. Even when multiple variants are combined to predict PC risk, they can explain only $10-20 \%$ of the genetic risk of

Published by Bioscientifica Ltd 
the given disease, indicating missing heritability (Cirulli \& Goldstein 2010). Furthermore, GWAS signals have rarely been tracked to causal variants. Although it is still not easy to identify rare variants that are assumed to have a larger effect on susceptibility to common diseases (Cirulli \& Goldstein 2010), a few rare variants have been identified that confer a substantial disease risk. Several linkage studies on hereditary PCs and early-onset PCs identified the chromosome 7q21-22 region as one of the most critical regions responsible for hereditary PCs. There are 202 genes in this critical region and NGS analysis identified rare variants of the HOXB13 gene, which is highly expressed in the prostate and is likely to be involved with the development of the prostate or urological system. While a rare variant of HOXB13 G84E was observed in $0.1-0.2 \%$ of the control population, the patients of hereditary PC or early-onset PC had 1-3\% with an OR of 2.7-5.1 (Ewing et al. 2012). WGS in an Icelandic population that identified a rare variant in the PC critical region at chromosome $8 q 24$, whose frequency was $0.5 \%$ in the control population, which is independent of the reported SNPs or loci at chromosome 8q24 (Gudmundsson et al. 2012). Now next-generation GWAS are focusing on rare variants. WGS or WES can identify rare variants (frequency $\sim 0.1$ or $0.5 \%$ ) in thousands of the affected population, and these variants on custom SNP chips can be screened for GWAS on $\sim 10000$ case controls. Owing to their low frequency, these analyses are required to scan a large number of samples to produce sufficient statistical power. Hence, it is critical to collect such a large sample size in the bio-banks or consortium worldwide.

\section{Somatic mutation analysis by NGS technology}

There is increasing evidence that the somatic mutation burden in an individual's cancer drives tumor formation, influences disease progression, and affects sensitivity to therapy (Fig. 2). Common somatic mutations in PC include loss of NKX3.1 and PTEN, and AR amplification or point mutations. NKX3.1 at chromosome $8 p 21$ is frequently subject to loss of heterozygosity ( $\mathrm{LOH}$ ) in human PCs, and it has been recognized to function as a tumor suppressor of prostate (Bova et al. 1993), although somatic point mutations of NKX3.1 were not frequently detected in PCs (Voeller et al. 1997). PTEN at chromosome $10 q 23$ is also frequently subject to $\mathrm{LOH}$ or homozygous deletion in many types of human cancers, and it is inactivated by point mutations in $20-40 \%$ of PCs (Li et al. 1997). Pten $^{+/-}$mice have prostatic hyperplasia and dysplasia; prostatic intraepithelial neoplasia (PIN) develops in $\mathrm{Pten}^{+/-} \mathrm{Nk} \times 3.1^{+/-}$and $\mathrm{Pten}^{+/-} \mathrm{Nk} \times 3.1^{-/-}$ mice (Kim et al. 2002), which indicate their tumor suppressor feature in prostate. In 2005, fusion transcripts of ETS family transcription factors with androgen-responsive promoters were discovered, which were driven by a genomic rearrangement (Tomlins et al. 2005). The TMPRSS2-ERG gene fusion and other ETS fusion genes have been causally linked to cancer progression because it promotes invasion, and overexpression of the fusion product in mice shows greatly enhanced PC development (Carver et al. 2009). Now recent rapid advances in sequencing technology (NGS) have enabled us to perform more comprehensive analysis such as WGS for human genome and cancer genome for $\$ 5000$ in a few days, and its cost is expected to become less than $\$ 1000$ in a few years. WGS can comprehensively detect almost all single-nucleotide variants, copy number variants, structure changes, and foreign genomes such as integrated virus (Fig. 1). Some projects in ICGC and other groups are analyzing PC genomes by WGS or WES integrated with RNA-Seq and DNA methylation analysis (http://www.icgc.org/) now. It is also required to examine somatic mutations of PC in different ethnic groups (African and Asian PCs) as well as germline variants because PC genomics and its biological behavior show some ethnic differences.

\section{WGS and WES of PC}

Initial WGS analysis on seven PCs with a Gleason grade 7 or higher (Berger et al. 2011) revealed that a number of genomic rearrangements were present in PC genomes and their breakpoints were enriched near open chromatin, AR, and ERG DNA binding site, leading to several types of ETS gene fusions. Other genomic rearrangements were observed to affect PTEN and PTEN-interacting proteins, indicating the effect of the PTEN pathway on prostate carcinogenesis. On average, PCs harbored 13-40 nonsilent coding somatic mutations and $\sim 1.0$ mutations per $\mathrm{Mb}$. This number is relatively low compared with the mutation numbers of other types of solid tumors. WES on 23 PC xenografts in mice (Kumar et al. 2011) was reported, and this study identified a number of somatic mutations, because they did not analyze the normal control genome and their data were likely to be contaminated by mouse genome sequences. WES on 112 PC samples (Barbieri et al. 2012) identified recurrent mutations in multiple genes, including SPOP, MED12, and FOXA1. SPOP mutations were identified in $6-13 \%$ of PCs, and it is likely to be involved in cell invasion. It is interesting that SPOP mutations occurred mutually exclusively in PC with $E R G$

Published by Bioscientifica Ltd 


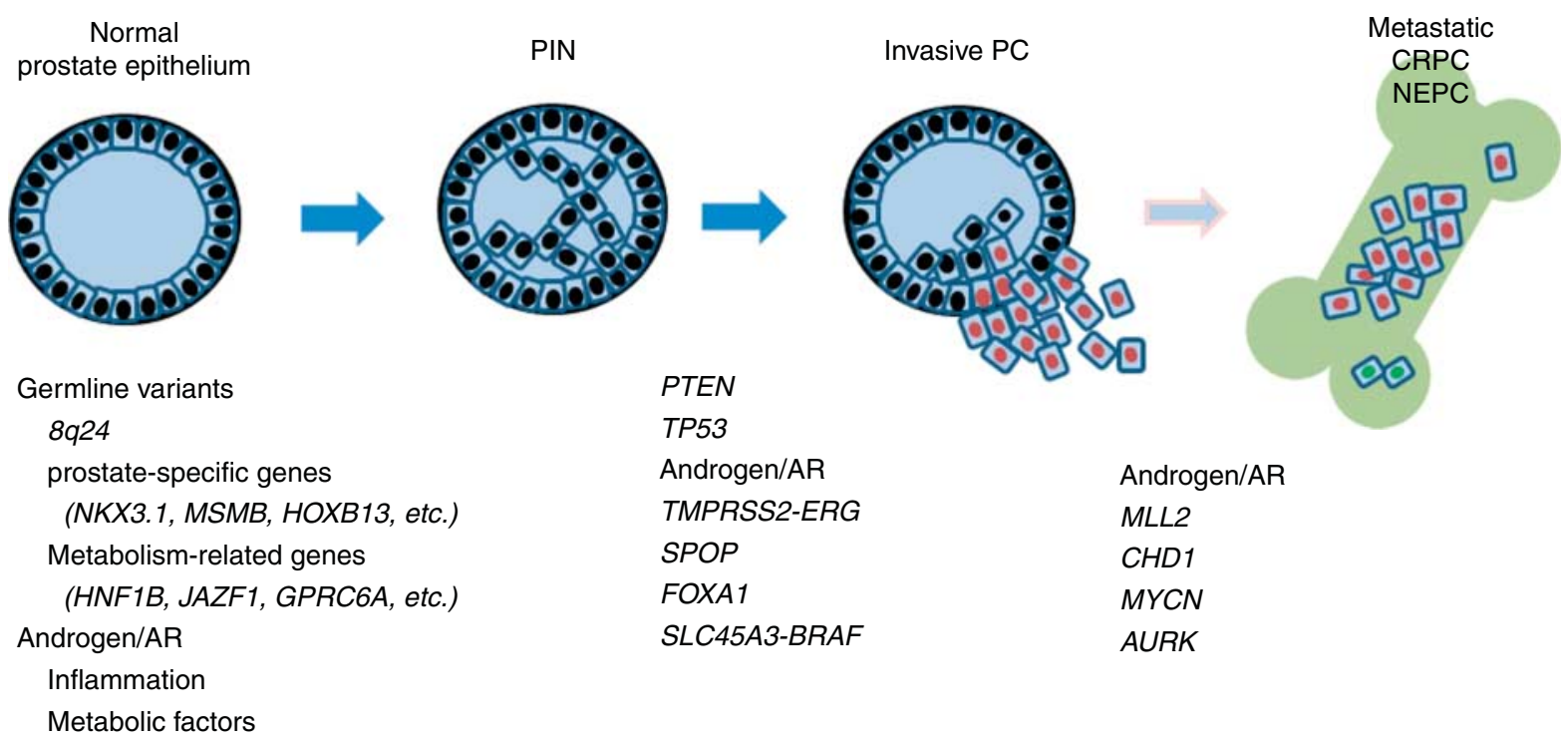

Figure 2

Prostate cancer (PC) development and progression with the accumulation of various somatic mutations on the background of germline variants.

rearrangements, and it was also detected in PC precursor, high-grade PIN, suggesting that SPOP mutations comprise an early event in prostate carcinogenesis as well as $E R G$ rearrangements. Another WES analysis was performed focusing on 50 CRPCs (Grasso et al. 2012). This study identified recurrent mutations of chromatin regulators, including MLL2, CHD1, and FOXA1. These mutated genes are likely to be involved with androgen/AR signaling and confer deregulated AR signaling and a CR phenotype. WGS on 11 early-onset PCs was also conducted, which showed age-related differences in structure rearrangement formations. Compared with elderly-onset PC, these earlyonset PCs demonstrated enrichment for androgen-driven structural rearrangements involving ETS family genes (Weischenfeldt et al. 2013), suggesting that early-onset PC development is predominantly driven by the androgen and AR signaling pathway.

\section{RNA-Seq and fusion genes in PC}

RNA-Seq (whole transcriptome sequencing) can provide not only a gene expression profile but also information about splicing changes, non-annotated ncRNA expression, and RNA editing. Most importantly, for PC genomics, RNA-Seq analysis can detect many types of recurrent fusion genes. ETS family gene fusions, including TMPRSS2$E R G$, were discovered in 2005, and most PCs are characterized by the presence of recurrent gene fusions
The androgen/AR signaling pathway plays a consistent and critical role in all steps of PC development and progression.

primarily involving androgen-regulated upstream genes, TMPRSS2, KLK2, and SLC45A3, fused to one of the genes of the ETS family of oncogenic transcription factors $(E R G$, ETV1, ETV4, or ETV5) (Maher et al. 2009). These fusion events are usually driven by genomic rearrangements in PC genomes. Recent RNA-Seq analysis detected one readthrough chimera, SLC45A3-ELK4, between the fourth exon of $S L C 45 A 3$ with exon 2 of $E L K 4$, a member of the ETS transcription factor family, and this fusion event was not driven by genomic rearrangements, but cis-splicing between the two adjacent genes (Maher et al. 2009, Zhang et al. 2012). In addition to the ETS family gene fusions, RNA-Seq analysis on 25 PC samples discovered fusion transcripts involving non-ETS genes such as CDKN1A (p21), CD9, and IKBKB (IKK $\beta)$, genes known to exhibit key biological roles in cellular homeostasis, as well as the oncogene PIGU and the tumor suppressor gene RSRC2 (Pflueger et al. 2011). Another RNA-Seq analysis on 14 Chinese PCs uncovered a recurrent fusion gene between USP9Y and TTY15 on chromosome Y, and a fusion event that arose from an interchromosomal translocation involving CTAGE5 and KHDRBS3 (Ren et al. 2012). A recent study by RNA-Seq discovered $R A F$ kinase gene fusions: SLC45A3-BRAF, ESRP1-RAF1, and RAF1-ESRP1 in advanced PCs. Although they were detected in only $1-2 \%$ of PCs, RAF kinase fusions represent the first 'actionable' fusions in PCs that do not involve an ETS family member (Palanisamy et al. 2010). RNA-Seq

Published by Bioscientifica Ltd. 
analysis can detect non-annotated transcripts, different from the microarrays, and systematic RNA-Seq analysis on 102 PC samples discovered more than 100 novel PC-specific ncRNAs and demonstrated that a novel lincRNA PCAT1 is a transcriptional repressor implicated in a subset of PC patients (Prensner et al. 2011).

\section{Neuroendocrine PC genome}

Neuroendocrine PC (NEPC) is a rare subtype of PC affecting only $0.5-2 \%$ of patients with PC, but NEPCs more frequently arise after castration therapy for prostate adenocarcinoma, although it can arise de novo (Palmgren et al. 2007). Focal neuroendocrine differentiation is detected in some $10 \%$ of localized PCs and increases with disease progression, indicating that these clones are evolved to a NEPC phenotype after castration (Beltran et al. 2011). New AR inhibitors and blockers of androgen production are now available, and 'complete' castration will be established and be a standard therapy for recurrent and metastatic CRPCs (Haddad \& Garcia 2012). Hence, the number of patients with the NEPC phenotype will increase (Fig. 2), and more research and clinical focus will be put into the study of NEPCs. TMPRSS2-ERG has been reported in $\sim 50 \%$ of NEPCs, suggesting that NEPC is clonally derived and evolved from PC (Lotan et al. 2011). RNA-Seq analysis of seven NEPCs revealed overexpression and amplification of AURKA and MYCN in 40\% of NEPCs and $5 \%$ of PCs (Beltran et al. 2011).

\section{Conclusions}

Recent innovation of high-throughput genomic technology has enabled us to analyze PC genomics more comprehensively, more precisely, and on a larger scale. Based on this valuable information, our understanding of PC genomics and biology is increasing. Germline research can help to establish the risk prediction and prevention of PC, while somatic research can provide information on novel molecular targets and biomarkers and a rationale for molecular sub-classification. The final goal is personalized medicine for PC diagnosis, treatment, and prevention (Fig. 1). However, through GWAS and sequencing analysis, we have recognized more complexity and heterogeneity in the human PC genome than expected. Therefore, to gain further new insights into PC genomics, we have to analyze a larger sample size in each ethnic or racial group. It is still too early and primitive to translate these high-throughput data into the clinic because the majority of these genomic data lack biological significance; it is difficult to interpret these huge data sets in all biological and clinical aspects. Hence, in addition to discovery by large-scale analysis, we have to employ functional and informatic approaches to better capitalize on the genomic data and to shed light on the biological significance of the genomic alterations or variants that have been identified by high-throughput genomic technologies.

\section{Declaration of interest}

The author declares that there is no conflict of interest that could be perceived as prejudicing the impartiality of the review.

\section{Funding}

This work has been financially supported by the BioBank Japan Project of the Ministry of Education, Culture, Sports, Sciences and Technology of the Japanese government, by Research grant \#22390306 (H Nakagawa) from the Japan Society for the Promotion of Science, and by the Takeda Science Foundation.

\section{References}

Akamatsu S, Takata R, Ashikawa K, Hosono N, Kamatani N, Fujioka T, Ogawa O, Kubo M, Nakamura Y \& Nakagawa H 2010 A functional variant in NKX3.1 associated with prostate cancer susceptibility downregulates NKX3.1 expression. Human Molecular Genetics 19 4265-4272. (doi:10.1093/hmg/ddq350)

Akamatsu S, Takahashi A, Takata R, Kubo M, Inoue T, Morizono T, Tsunoda T, Kamatani N, Haiman CA, Wan P et al. 2012 Reproducibility, performance, and clinical utility of a genetic risk prediction model for prostate cancer in Japanese. PLOS ONE 7 e46454. (doi:10.1371/journal.pone.0046454)

Albertsen PC 2010 Treatment of localized prostate cancer: when is active surveillance appropriate? Nature Reviews. Clinical Oncology 7 394-400. (doi:10.1038/nrclinonc.2010.63)

Al Olama AA, Kote-Jarai Z, Giles GG, Guy M, Morrison J, Severi G, Leongamornlert DA, Tymrakiewicz M, Jhavar S, Saunders E et al. 2009 Multiple loci on 8q24 associated with prostate cancer susceptibility. Nature Genetics 41 1058-1060. (doi:10.1038/ng.452)

Al Olama A, Kote-Jarai Z, Schumacher FR, Wiklund F, Berndt SI, Benlloch S, Giles GG, Severi G, Neal DE, Hamdy FC et al. 2013 A meta-analysis of genome-wide association studies to identify prostate cancer susceptibility loci associated with aggressive and non-aggressive disease. Human Molecular Genetics 22 408-415. (doi:10.1093/hmg/dds425)

Amundadottir LT, Sulem P, Gudmundsson J, Helgason A, Baker A, Agnarsson BA, Sigurdsson A, Benediktsdottir KR, Cazier JB, Sainz J et al. 2006 A common variant associated with prostate cancer in European and African populations. Nature Genetics 38 652-658. (doi:10.1038/ ng1808)

Barbieri CE, Baca SC, Lawrence MS, Demichelis F, Blattner M, Theurillat JP, White TA, Stojanov P, Van Allen E, Stransky N et al. 2012 Exome sequencing identifies recurrent SPOP, FOXA1 and MED12 mutations in prostate cancer. Nature Genetics 44 685-689. (doi:10.1038/ng.2279)

Beke L, Nuytten M, Van Eynde A, Beullens M \& Bollen M 2007 The gene encoding the prostatic tumor suppressor PSP94 is a target for repression by the Polycomb group protein EZH2. Oncogene $264590-4595$. (doi:10.1038/sj.onc.1210248) 
Beltran H, Rickman DS, Park K, Chae SS, Sboner A, MacDonald TY, Wang Y, Sheikh KL, Terry S, Tagawa ST et al. 2011 Molecular characterization of neuroendocrine prostate cancer and identification of new drug targets. Cancer Discovery 1 487-495. (doi:10.1158/2159-8290.CD-11-0130)

Berger MF, Lawrence MS, Demichelis F, Drier Y, Cibulskis K, Sivachenko AY, Sboner A, Esgueva R, Pflueger D, Sougnez C et al. 2011 The genomic complexity of primary human prostate cancer. Nature $\mathbf{4 7 0} 214-420$. (doi:10.1038/nature09744)

Bonovas S, Filioussi K \& Tsantes A 2004 Diabetes mellitus and risk of prostate cancer: a meta-analysis. Diabetologia 47 1071-1078. (doi:10.1007/s00125-004-1415-6)

Bova GS, Carter BS, Bussemakers MJ, Emi M, Fujiwara Y, Kyprianou N, Jacobs SC, Robinson JC, Epstein JI, Walsh PC et al. 1993 Homozygous deletion and frequent allelic loss of chromosome 8p22 loci in human prostate cancer. Cancer Research 53 3869-3873.

Bubendorf L, Kononen J, Koivisto P, Schraml P, Moch H, Gasser TC, Willi N, Mihatsch MJ, Sauter G \& Kallioniemi OP 1999 Survey of gene amplifications during prostate cancer progression by high-throughout fluorescence in situ hybridization on tissue microarrays. Cancer Research $59803-806$

Carver BS, Tran J, Gopalan A, Chen Z, Shaikh S, Carracedo A, Alimonti A, Nardella C, Varmeh S, Scardino PT et al. 2009 Aberrant ERG expression cooperates with loss of PTEN to promote cancer progression in the prostate. Nature Genetics 41 619-624. (doi:10.1038/ng.370)

Chang BL, Cramer SD, Wiklund F, Isaacs SD, Stevens VL, Sun J, Smith S, Pruett K, Romero LM, Wiley KE et al. 2009 Fine mapping association study and functional analysis implicate a SNP in MSMB at 10q11 as a causal variant for prostate cancer risk. Human Molecular Genetics $\mathbf{1 8}$ 1368-1375. (doi:10.1093/hmg/ddp035)

Chatterjee N, Wheeler B, Sampson J, Hartge P, Chanock SJ \& Park JH 2013 Projecting the performance of risk prediction based on polygenic analyses of genome-wide association studies. Nature Genetics $\mathbf{4 5}$ 400-405. (doi:10.1038/ng.2579)

Chu LW, Meyer TE, Li Q, Menashe I, Yu K, Rosenberg PS, Huang WY, Quraishi SM, Kaaks R, Weiss JM et al. 2010 Association between genetic variants in the $8 \mathrm{q} 24$ cancer risk regions and circulating levels of androgens and sex hormone-binding globulin. Cancer Epidemiology, Biomarkers \& Prevention 19 1848-1854. (doi:10.1158/ 1055-9965.EPI-10-0101)

Chung S, Nakagawa H, Uemura M, Piao L, Ashikawa K, Hosono N, Takata R, Akamatsu S, Kawaguchi T, Morizono T et al. 2011 Association of a novel long non-coding RNA in $8 q 24$ with prostate cancer susceptibility. Cancer Science 102 245-252. (doi:10.1111/j.1349-7006.2010.01737.x)

Cirulli ET \& Goldstein DB 2010 Uncovering the roles of rare variants in common disease through whole-genome sequencing. Nature Reviews. Genetics 11 415-425. (doi:10.1038/nrg2779)

Easton DF, Pooley KA, Dunning AM, Pharoah PD, Thompson D, Ballinger DG, Struewing JP, Morrison J, Field H, Luben R et al. 2007 Genome-wide association study identifies novel breast cancer susceptibility loci. Nature 447 1087-1093. (doi:10.1038/nature05887)

Eeles RA, Kote-Jarai Z, Giles GG, Al Olama A, Guy M, Jugurnauth SK, Mulholland S, Leongamornlert DA, Edwards SM, Morrison J et al. 2008 Multiple newly identified loci associated with prostate cancer susceptibility. Nature Genetics 40 316-321. (doi:10.1038/ng.90)

Eeles RA, Kote-Jarai Z, Al Olama AA, Giles GG, Guy M, Severi G, Muir K, Hopper JL, Henderson BE, Haiman CA et al. 2009 Identification of seven new prostate cancer susceptibility loci through a genome-wide association study. Nature Genetics 41 1116-1121. (doi:10.1038/ng.450)

Eeles RA, Al Olama A, Benlloch S, Saunders EJ, Leongamornlert DA, Tymrakiewicz M, Ghoussaini M, Luccarini C, Dennis J, JugurnauthLittle $S$ et al. 2013 Identification of 23 new prostate cancer susceptibility loci using the iCOGS custom genotyping array. Nature Genetics $\mathbf{4 5}$ 385-391. (doi:10.1038/ng.2560)

Ewing CM, Ray AM, Lange EM, Zuhlke KA, Robbins CM, Tembe WD, Wiley KE, Isaacs SD, Johng D, Wang Y et al. 2012 Germline mutations in HOXB13 and prostate-cancer risk. New England Journal of Medicine 366 141-149. (doi:10.1056/NEJMoa1110000)

Freedman ML, Monteiro AN, Gayther SA, Coetzee GA, Risch A, Plass C, Casey G, De Biasi M, Carlson C, Duggan D et al. 2011 Principles for the post-GWAS functional characterization of cancer risk loci. Nature Genetics 43 513-518. (doi:10.1038/ng.840)

Ghoussaini M, Song H, Koessler T, Al Olama AA, Kote-Jarai Z, Driver KE, Pooley KA, Ramus SJ, Kjaer SK, Hogdall E et al. 2008 Multiple loci with different cancer specificities within the 8q24 gene desert. Journal of the National Cancer Institute 100 962-966. (doi:10.1093/jnci/djn190)

Grasso CS, Wu YM, Robinson DR, Cao X, Dhanasekaran SM, Khan AP, Quist MJ, Jing X, Lonigro RJ, Brenner JC et al. 2012 The mutational landscape of lethal castration-resistant prostate cancer. Nature $\mathbf{4 8 7}$ 239-243. (doi:10.1038/nature11125)

Gronberg H 2003 Prostate cancer epidemiology. Lancet 361 859-864. (doi:10.1016/S0140-6736(03)12713-4)

Gudmundsson J, Sulem P, Manolescu A, Amundadottir LT, Gudbjartsson D, Helgason A, Rafnar T, Bergthorsson JT, Agnarsson BA, Baker A et al. 2007 Genome-wide association study identifies a second prostate cancer susceptibility variant at 8q24. Nature Genetics 39 631-637. (doi:10.1038/ ng1999)

Gudmundsson J, Besenbacher S, Sulem P, Gudbjartsson DF, Olafsson I, Arinbjarnarson S, Agnarsson BA, Benediktsdottir KR, Isaksson HJ, Kostic JP et al. 2010 Genetic correction of PSA values using sequence variants associated with PSA levels. Science Translational Medicine 2 62ra92. (doi:10.1126/scitranslmed.3001513)

Gudmundsson J, Sulem P, Gudbjartsson DF, Masson G, Agnarsson BA, Benediktsdottir KR, Sigurdsson A, Magnusson OT, Gudjonsson SA, Magnusdottir DN et al. 2012 A study based on whole-genome sequencing yields a rare variant at $8 \mathrm{q} 24$ associated with prostate cancer. Nature Genetics 44 1326-1329. (doi:10.1038/ng.2437)

Haddad H \& Garcia JA 2012 Novel agents for the management of castration-resistant prostate cancer. Current Opinion in Urology 22 175-782. (doi:10.1097/MOU.0b013e3283523ba0)

Haiman CA, Patterson N, Freedman ML, Myers SR, Pike MC, Waliszewska A, Neubauer J, Tandon A, Schirmer C, McDonald GJ et al. 2007 Multiple regions within $8 \mathrm{q} 24$ independently affect risk for prostate cancer. Nature Genetics 39 638-644. (doi:10.1038/ng2015)

Haiman CA, Chen GK, Blot WJ, Strom SS, Berndt SI, Kittles RA, Rybicki BA, Isaacs WB, Ingles SA, Stanford JL et al. 2011 Genome-wide association study of prostate cancer in men of African ancestry identified a susceptibility locus at 17q21. Nature Genetics 43 570-573. (doi:10.1038/ ng.839)

Hudson TJ, Anderson W, Artez A, Barker AD, Bell C, Bernabé RR, Bhan MK, Calvo F, Eerola I, Gerhard DS et al. 2010 International network of cancer genome projects. Nature 464 993-998. (doi:10.1038/nature08987)

Kim MJ, Cardiff RD, Desai N, Banach-Petrosky WA, Parsons R, Shen MM \& Abate-Shen C 2002 Cooperativity of Nkx3.1 and Pten loss of function in a mouse model of prostate carcinogenesis. PNAS 99 2884-2889. (doi:10.1073/pnas.042688999)

Konety BR, Bird VY, Deorah S \& Dahmoush L 2005 Comparison of the incidence of latent prostate cancer detected by autopsy before and after the prostate specific antigen era. Journal of Urology 174 1785-1788. (doi:10.1097/01.ju.0000177470.84735.55)

Kote-Jarai Z, Easton DF, Stanford JL, Ostrander EA, Schleutker J, Ingles SA, Schaid D, Thibodeau S, Dörk T, Neal D et al. 2008 Multiple novel prostate cancer predisposition loci confirmed by an international study: the PRACTICAL Consortium. Cancer Epidemiology, Biomarkers \& Prevention 17 2052-2061. (doi:10.1158/1055-9965.EPI-08-0317)

Kote-Jarai Z, Al Olama A, Giles GG, Severi G, Schleutker J, Weischer M, Campa D, Riboli E, Key T, Gronberg H et al. 2011 Seven prostate cancer susceptibility loci identified by a multi-stage genome-wide association study. Nature Genetics 43 785-789. (doi:10.1038/ng.882)

Kumar A, White TA, MacKenzie AP, Clegg N, Lee C, Dumpit RF, Coleman I, $\mathrm{Ng} \mathrm{SB}$, Salipante SJ, Rieder MJ et al. 2011 Exome sequencing identifies a 
spectrum of mutation frequencies in advanced and lethal prostate cancers. PNAS 108 17087-17092. (doi:10.1073/pnas.1108745108)

Li J, Yen C, Liaw D, Podsypanina K, Bose S, Wang SI, Puc J, Miliaresis C, Rodgers L, McCombie R et al. 1997 PTEN, a putative protein tyrosine phosphatase gene mutated in human brain, breast, and prostate cancer. Science 275 1943-1947. (doi:10.1126/science.275.5308.1943)

Li L, Yang Y, Yang G, Lu C, Yang M, Liu H \& Zong H 2011 The role of JAZF1 on lipid metabolism and related genes in vitro. Metabolism $60523-530$. (doi:10.1016/j.metabol.2010.04.021)

Lichtenstein P, Holm NV, Verkasalo PK, Iliadou A, Kaprio J, Koskenvuo M, Pukkala E, Skytthe A \& Hemminki K 2001 Environmental and heritable factors in the causation of cancer - analyses of cohorts of twins from Sweden, Denmark, and Finland. New England Journal of Medicine 343 78-85. (doi:10.1056/NEJM200007133430201)

Lindner TH, Njolstad PR, Horikawa Y, Bostad L, Bell GI \& Sovik O 1999 A novel syndrome of diabetes mellitus, renal dysfunction and genital malformation associated with a partial deletion of the pseudo-POU domain of hepatocyte nuclear factor-1ß. Human Molecular Genetics $\mathbf{8}$ 2001-2008. (doi:10.1093/hmg/8.11.2001)

Lotan TL, Gupta NS, Wang W, Toubaji A, Haffner MC, Chaux A, Hicks JL, Meeker AK, Bieberich CJ, De Marzo AM et al. 2011 ERG gene rearrangements are common in prostatic small cell carcinomas. Modern Pathology 24 820-828. (doi:10.1038/modpathol.2011.7)

Maher CA, Kumar-Sinha C, Cao X, Kalyana-Sundaram S, Han B, Jing X, Sam L, Barrette T, Palanisamy N \& Chinnaiyan AM 2009 Transcriptome sequencing to detect gene fusions in cancer. Nature 458 97-101. (doi:10.1038/nature07638)

Manolio TA 2010 Genomewide association studies and assessment of the risk of disease. New England Journal of Medicine 363 166-176. (doi:10.1056/NEJMra0905980)

Nakagawa H, Akamatsu S, Takata R, Takahashi A, Kubo M \& Nakamura Y 2012 Prostate cancer genomics, biology, and risk assessment through genome-wide association studies. Cancer Science 103 607-613. (doi:10.1111/j.1349-7006.2011.02193.x)

Nam RK, Zhang WW, Trachtenberg J, Seth A, Klotz LH, Stanimirovic A, Punnen S, Venkateswaran V, Toi A, Loblaw DA et al. 2009 Utility of incorporating genetic variants for the early detection of prostate cancer. Clinical Cancer Research 15 1787-1793. (doi:10.1158/ 1078-0432.CCR-08-1593)

Nguyen HH, Takata R, Akamatsu S, Shigemizu D, Tsunoda T, Furihata M, Takahashi A, Kubo M, Kamatani N, Ogawa O et al. 2012 IRX4 at 5p15 suppresses prostate cancer growth through the interaction with vitamin D receptor, conferring prostate cancer susceptibility. Human Molecular Genetics 21 2076-2085. (doi:10.1093/hmg/dds025)

Palanisamy N, Ateeq B, Kalyana-Sundaram S, Pflueger D, Ramnarayanan K, Shankar S, Han B, Cao Q, Cao X, Suleman K et al. 2010 Rearrangements of the RAF kinase pathway in prostate cancer, gastric cancer and melanoma. Nature Medicine 16 793-798. (doi:10.1038/nm.2166)

Palmgren JS, Karavadia SS \& Wakefield MR 2007 Unusual and underappreciated: small cell carcinoma of the prostate. Seminars in Oncology 34 22-29. (doi:10.1053/j.seminoncol.2006.10.026)

Pflueger D, Terry S, Sboner A, Habegger L, Esgueva R, Lin PC, Svensson MA, Kitabayashi N, Moss BJ, MacDonald TY et al. 2011 Discovery of non-ETS gene fusions in human prostate cancer using next-generation RNA sequencing. Genome Research 21 56-67. (doi:10.1101/gr.110684.110)

Pi M, Chen L, Huang MZ, Zhu W, Ringhofer B, Luo J, Christenson L, Li B, Zhang J, Jackson PD et al. 2008 GPRC6A null mice exhibit osteopenia, feminization and metabolic syndrome. PLOS ONE 3 e3858. (doi:10.1371/journal.pone.0003858)

Pomerantz MM, Ahmadiyeh N, Jia L, Herman P, Verzi MP, Doddapaneni H, Beckwith CA, Chan JA, Hills A, Davis ML et al. 2009 The 8q24 cancer risk variant rs6983267 shows long-range interaction with MYC in colorectal cancer. Nature Genetics 41 882-884. (doi:10.1038/ng.403)

Pontoglio M 2000 Hepatocyte nuclear factor 1, a transcription factor at the crossroads of glucose homeostasis. Journal of the American Society of Nephrology 11 S140-S143.
Prensner JR, Iyer MK, Balbin OA, Dhanasekaran SM, Cao Q, Brenner JC, Laxman B, Asangani IA, Grasso CS, Kominsky HD et al. 2011 Transcriptome sequencing across a prostate cancer cohort identifies PCAT-1, an unannotated lincRNA implicated in disease progression. Nature Biotechnology 29 742-749. (doi:10.1038/nbt.1914)

Ren S, Peng Z, Mao JH, Yu Y, Yin C, Gao X, Cui Z, Zhang J, Yi K, Xu W et al. 2012 RNA-seq analysis of prostate cancer in the Chinese population identifies recurrent gene fusions, cancer-associated long noncoding RNAs and aberrant alternative splicings. Cell Research 22 806-821. (doi:10.1038/cr.2012.30)

Schaid DJ 2004 The complex genetic epidemiology of prostate cancer. Human Molecular Genetics 13 R103-R121. (doi:10.1093/hmg/ddh072)

Scher HI \& Sawyers CL 2005 Biology of progressive, castration-resistant prostate cancer: directed therapies targeting the androgen-receptor signaling axis. Journal of Clinical Oncology 23 8253-8261. (doi:10.1200/ JCO.2005.03.4777)

Soranzo N, Rivadeneira F, Chinappen-Horsley U, Malkina I, Richards JB, Hammond N, Stolk L, Nica A, Inouye M, Hofman A et al. 2009 Metaanalysis of genome-wide scans for human adult stature identifies novel Loci and associations with measures of skeletal frame size. PLoS Genetics 5 e1000445. (doi:10.1371/journal.pgen.1000445)

Spurdle AB, Thompson DJ, Ahmed S, Ferguson K, Healey CS, O'Mara T, Walker LC, Montgomery SB, Dermitzakis ET, Fahey P et al. 2011 Genome-wide association study identifies a common variant associated with risk of endometrial cancer. Nature Genetics 43 451-454. (doi:10.1038/ng.812)

Sun J, Zheng SL, Wiklund F, Isaacs SD, Purcell LD, Gao Z, Hsu FC, Kim ST, Liu W, Zhu Y et al. 2008 Evidence for two independent prostate cancer risk-associated loci in the HNF1B gene at 17q12. Nature Genetics 40 1153-1155. (doi:10.1038/ng.214)

Takata R, Akamatsu S, Kubo M, Takahashi A, Hosono N, Kawaguchi T, Tsunoda T, Inazawa J, Kamatani N, Ogawa O et al. 2010 Genome-wide association study identifies five new susceptibility loci for prostate cancer in the Japanese population. Nature Genetics 42 751-754. (doi:10.1038/ng.635)

Taplin ME, Bubley GJ, Shuster TD, Frantz ME, Spooner AE, Ogata GK, Keer HN \& Balk SP 1995 Mutation of the androgen-receptor gene in metastatic androgen-independent prostate cancer. New England Journal of Medicine 332 1393-1398. (doi:10.1056/ NEJM199505253322101)

Thomas G, Jacobs KB, Yeager M, Kraft P, Wacholder S, Orr N, Yu K, Chatterjee N, Welch R, Hutchinson A et al. 2008 Multiple loci identified in a genome-wide association study of prostate cancer. Nature Genetics 40 310-315. (doi:10.1038/ng.91)

Tomlins SA, Rhodes DR, Perner S, Dhanasekaran SM, Mehra R, Sun XW, Varambally S, Cao X, Tchinda J, Kuefer R et al. 2005 Recurrent fusion of TMPRSS2 and ETS transcription factor genes in prostate cancer. Science 310 644-648. (doi:10.1126/science.1117679)

Tomlinson I, Webb E, Carvajal-Carmona L, Broderick P, Kemp Z, Spain S, Penegar S, Chandler I, Gorman M, Wood W et al. 2007 A genome-wide association scan of tag SNPs identifies a susceptibility variant for colorectal cancer at 8q24.21. Nature Genetics 39 984-988. (doi:10.1038/ ng2085)

Tuupanen S, Turunen M, Lehtonen R, Hallikas O, Vanharanta S, Kivioja T, Björklund M, Wei G, Yan J, Niittymäki I et al. 2009 The common colorectal cancer predisposition SNP rs6983267 at chromosome 8q24 confers potential to enhanced Wnt signaling. Nature Genetics 41 885-890. (doi:10.1038/ng.406)

Voeller HJ, Augustus M, Madike V, Bova GS, Carter KC \& Gelmann EP 1997 Coding region of NKX3.1, a prostate-specific homeobox gene on 8 p21, is not mutated in human prostate cancers. Cancer Research $\mathbf{5 7}$ 4455-4459.

Wang X, Kruithof-de Julio M, Economides KD, Walker D, Yu H, Halili MV, Hu Y-P, Price SM, Abate-Shen C \& Shen MM 2009 A luminal epithelial stem cell that is a cell of origin for prostate cancer. Nature 461 495-500. (doi:10.1038/nature08361) 
Weischenfeldt J, Simon R, Feuerbach L, Schlangen K, Weichenhan D, Minner S, Wuttig D, Warnatz HJ, Stehr H, Rausch T et al. 2013 Integrative genomic analyses reveal an androgen-driven somatic alteration landscape in early-onset prostate cancer. Cancer Cell $\mathbf{2 3}$ 159-170. (doi:10.1016/j.ccr.2013.01.002)

Wiehagen KR, Corbo-Rodgers E, Li S, Staub ES, Hunter CA, Morrisey EE \& Maltzman JS 2012 Foxp4 is dispensable for T cell development, but required for robust recall responses. PLoS ONE 7 e42273. (doi:10.1371/ journal.pone.0042273)

Xu J, Zheng SL, Isaacs SD, Wiley KE, Wiklund F, Sun J, Kader AK, Li G, Purcell LD, Kim ST et al. 2010 Inherited genetic variant predisposes to aggressive but not indolent prostate cancer. PNAS 107 2136-2140. (doi:10.1073/pnas.0914061107)

Xu J, Mo Z, Ye D, Wang M, Liu F, Jin G, Xu C, Wang X, Shao Q, Chen Z et al. 2012 Genome-wide association study in Chinese men identifies two new prostate cancer risk loci at 9q31.2 and 19q13.4. Nature Genetics $\mathbf{4 4}$ 1231-1235. (doi:10.1038/ng.2424)
Yeager M, Orr N, Hayes RB, Jacobs KB, Kraft P, Wacholder S, Minichiello MJ, Fearnhead P, Yu K, Chatterjee N et al. 2007 Genome-wide association study of prostate cancer identifies a second risk locus at 8q24. Nature Genetics 39 645-649. (doi:10.1038/ng2022)

Zhang Y, Gong M, Yuan H, Park HG, Frierson HF \& Li H 2012 Chimeric transcript generated by cis-splicing of adjacent genes regulates prostate cancer cell proliferation. Cancer Discovery 2 598-607. (doi:10.1158/ 2159-8290.CD-12-0042)

Zheng SL, Sun J, Wiklund F, Smith S, Stattin P, Li G, Adami H-O, Hsu F-C, Zhu Y, Bälter K et al. 2008 Cumulative association of five genetic variants with prostate cancer. New England Journal of Medicine 358 910-919. (doi:10.1056/NEJMoa075819)

Zheng SL, Sun J, Wiklund F, Gao Z, Stattin P, Purcell LD, Adami HO, Hsu FC, Zhu Y, Adolfsson J et al. 2009 Genetic variants and family history predict prostate cancer similar to prostate-specific antigen. Clinical Cancer Research 15 1105-1111. (doi:10.1158/1078-0432. CCR-08-1743)

Received in final form 22 April 2013

Accepted 23 April 2013

Made available online as an Accepted Preprint

26 April 2013 http://erc.endocrinology-journals.org DOI: 10.1530/ERC-13-0113
(C) 2013 Society for Endocrinology Printed in Great Britain
Published by Bioscientifica Ltd. 